\title{
La peste: contagio y desencuentro
}

\author{
Dr. Baltasar Aguilar Fleitas
}

"Los curiosos acontecimientos que constituyen el tema de esta crónica se produjeron en el año 194... en Orán. Para la generalidad resultaron enteramente fuera de lugary un poco aparte de lo cotidiano (...)

La ciudad, en sí misma, hay que confesarlo, es fea. Su aspecto es tranquilo (...)

El modo más cómodo de conocer una ciudad es averiguar cómo se trabaja en ella, cómo se ama y cómo se muere. En nuestra ciudad, por efecto del clima, todo ello se hace igual, con el mismo aire frenético y ausente. Es decir, que se aburre uno y se dedica a adquirir hábitos. Nuestros conciudadanos trabajan mucho pero siempre para enriquecerse. Se interesan, sobre todo, por el comercio, y se ocupan principalmente de hacer negocios. Naturalmente, también les gustan las expansiones simples: las mujeres, el cine y los baños de mar. Pero, muy sensatamente, reservan los placeres para el sábado después del mediodía y el domingo, procurando los otros días de la semana, hacer mucho dinero.

Por las tardes, cuando dejan sus despachos, se reúnen a una hora fija en los cafés, se pasean por un determinado bulevar o se asoman al balcón. Los deseos de la gente joven son violentos y breves, mientras que los vicios de los mayores no exceden de las francachelas, los banquetes de camaradería y los círculos donde se juega fuerte al azar de las cartas (...)

Los hombres y mujeres o bien se devoran rápidamente en eso que se llama el acto de amor, o bien se crean el compromiso de una larga costumbre a dúo. (...) En Orán, como en otras partes, por falta de tiempo y reflexión, se ve uno obligado a amar sin darse cuenta.

Lo más original de nuestra ciudad es la dificultad que puede uno encontrar para morir. (...) los extremos del clima, la importancia de los negocios, la insignificancia de lo circundante, la brevedad del crepúsculo y la calidad de los placeres, todo exige buena salud. Un enfermo necesita soledad. Imagi- nese entonces al que está en trance de morir como cogido en una trampa (...) en el mismo momento en que toda una población en los teléfonos o en los cafés, habla de letras de cambio, de conocimientos, de descuentos.

(...) Esta ciudad, sin nada pintoresco, sin vegetación y sin alma, acaba por servir de reposo y al fin se adormece uno en ella".

El texto citado pertenece al libro La peste ${ }^{(1)} \mathrm{de}$ Albert Camus (1947). El autor, de manera magistral, nos describe la ciudad argelina de Orán, con costa hacia el Mediterráneo.

Salvando lógicas diferencias, la narración puede aplicarse a cualquier ciudad que transcurre sus días con tranquilidad y apacible rutina, sin advertir nada que pueda significar un llamado de atención o un peligro alarmante. Cuando las personas se dedican a seguir obedientemente el programa que han elegido como más conveniente a su interés colectivo, la navegación vital se hace en aguas calmas, predecibles y con un puerto siempre a la vista por si es necesario. La rutina cotidiana apaga los sistemas de alarma, impide la introspección y adormece la crítica sobre los riesgos que se corren como consecuencia de las acciones de los hombres.

Camus nos refuerza esa idea: "Siendo así las cosas, se admitirá fácilmente que no hubiese nada que hiciera esperar a nuestros conciudadanos, los acontecimientos que se produjeron a principios de aquel año".

¿Qué ocurrió en esa entumecida ciudad?

"La mañana del 16 de abril, el doctor Bernard Rieux, al salir de su habitación, tropezó con una rata muerta en medio del rellano de la escalera. En el primer momento no hizo más que apartar hacia un lado el animal y bajar sin preocuparse. Pero luego volvió sobre sus pasos para advertir al portero. (...) La presencia de aquella rata le había parecido únicamente extraña, mientras que para el portero constituía un verdadero escándalo.

Curso de Humanidades Médicas, Facultad de Medicina, Universidad de la República. Montevideo, Uruguay.

Correspondencia: Dr. Baltasar Aguilar Fleitas.

Correo electrónico: baltasaraguilarfleitas@gmail.com

$\mathrm{El}$ autor declara no tener conflictos de intereses.

Recibido Abr 28, 2020; aceptado May 5, 2020. 
Aquella misma tarde Rieux estaba en el pasillo del inmueble, buscando sus llaves antes de subir a su piso, cuando vio surgir del fondo oscuro del corredor una rata de gran tamaño con el pelaje mojado, que andaba torpemente. El animal se detuvo, pareció buscar el equilibrio, echó a correr hacia el doctor, se detuvo otra vez, dio una vuelta sobre sí misma, lanzando un pequeño grito y cayó al fin echando sangre por el hocico entreabierto.

(...) Rieux, intrigado, se decidió a comenzar sus visitas por los barrios extremos, donde habitaban sus pacientes más pobres. Las basuras se recogían allí tarde, y el auto a lo largo de las calles rectas y polvorientas de aquel barrio, rozaba las latas de detritos dejadas al borde de las aceras. En una calle llegó a contar una docena de ratas tiradas sobre los restos de las legumbres y trapos sucios".

Inopinadamente, como suele suceder, había comenzado la peste. Un signo por acá, otro que se suma al anterior, hasta conformar una serie de advertencias que al principio resulta difícil interpretar. La peste se había instalado en la ciudad y se disponía a dejar su secuela de muerte y sufrimiento.

\section{COVID-19 y la perspectiva histórica}

En nuestro país, como en Orán, estuvimos presenciando la epidemia de coronavirus en el mundo como un acontecimiento riesgoso pero lejano, exótico, hasta que aparecieron los primeros cuatro casos en el mes de marzo. A la fecha de escrito este artículo, se cuentan por cientos -y tal vez miles- los enfermos de COVID-19 y hay más de una decena de fallecidos. Las noticias ya no vienen de China, sino de Europa, de Estados Unidos y de los países vecinos, y son aterradoras. No existen fronteras para el SARS-CoV-2. Las personas y las familias practican la distancia física, el lavado de manos adquiere la importancia que no tenía desde la época de Semmelweis, la sociedad se sumerge en una crisis económica de impredecible alcance y recién ahora se empieza a hablar de la carga de dolor, sufrimiento y disrupción vital que sufren las personas confinadas, especialmente ancianos y niños.

Las pestes (entendiendo por tales a los efectos de este artículo, las epidemias y pandemias que han diezmado la población de territorios más o menos extensos), no son una novedad. Han estado presentes desde épocas remotas de la humanidad, por lo menos desde que el hombre dejó de ser recolector y cazador para agruparse en aldeas agrícolas. El aumento de la densidad poblacional y por consiguiente el mayor contacto entre las personas, así como la convivencia con animales, fueron factores determinantes de la aparición de estas enfermedades de

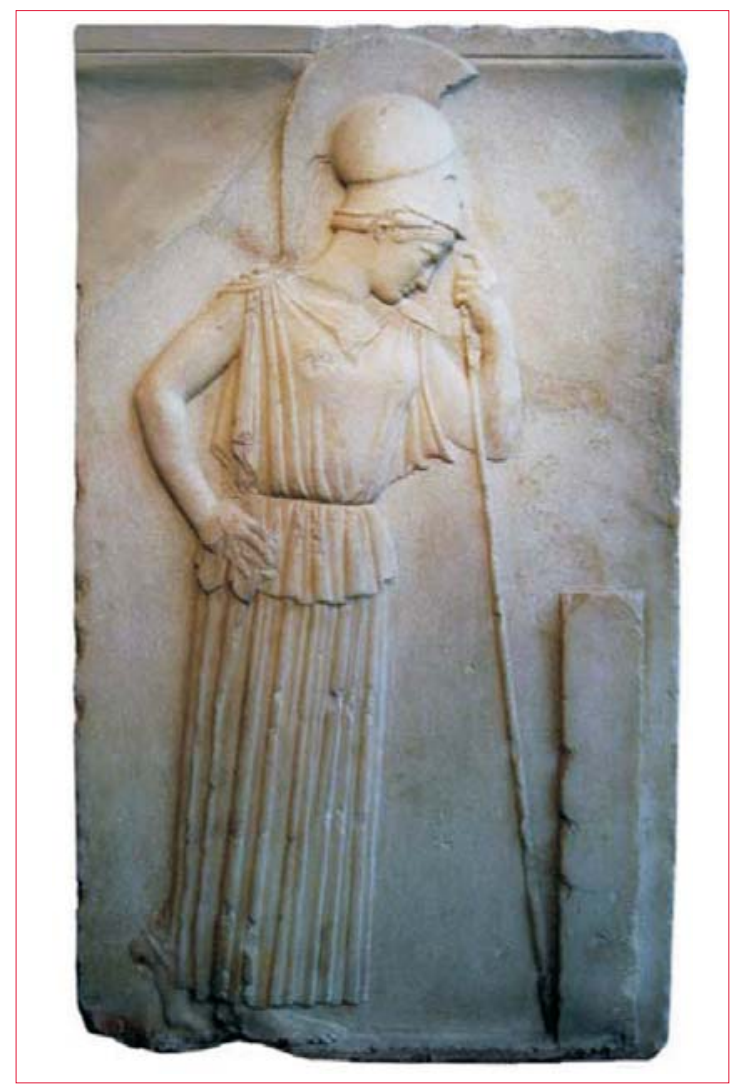

Figura 1. Atenea acongojada por los muertos en la epidemia de Atenas. Estela funeraria encontrada en el Partenón. (De elvuelodelalechuza.com)

masas. La globalización económica y tecnológica del mundo actual, y el tránsito de personas entre países y continentes, en lo que configura muchas veces un turismo irresponsable, hace que los agentes patógenos tengan un horizonte de distribución casi ilimitado. Diversos autores sostienen que de cinco grandes ecosistemas sanitarios (este asiático, sur de Asia, Medio Oriente, mediterráneo y subsahariano), se pasó al único ecosistema sanitario actual.

Solucionado el problema de la escasez de alimentos, las enfermedades transmisibles se convirtieron en el principal problema de la humanidad. "Después del hambre, el segundo gran enemigo de la humanidad fueron las pestes y las enfermedades infecciosas. Las ciudades, bulliciosas y conectadas por un torrente incesante de mercaderes, funcionarios y peregrinos, constituyeron a la vez los cimientos de la civilización humana y un caldo de cultivo ideal para los patógenos"(2).

Haré una sucinta revisión de los principales acontecimientos en la materia, sin ánimo de agotar el tema, e iré intercalando comentarios pertinentes a los hechos.

La epidemia más antigua registrada fue la de Atenas, en el $430 \mathrm{aC}$, durante las guerras del Peloponeso. Se trató de fiebre tifoidea. Según Tucídides, 


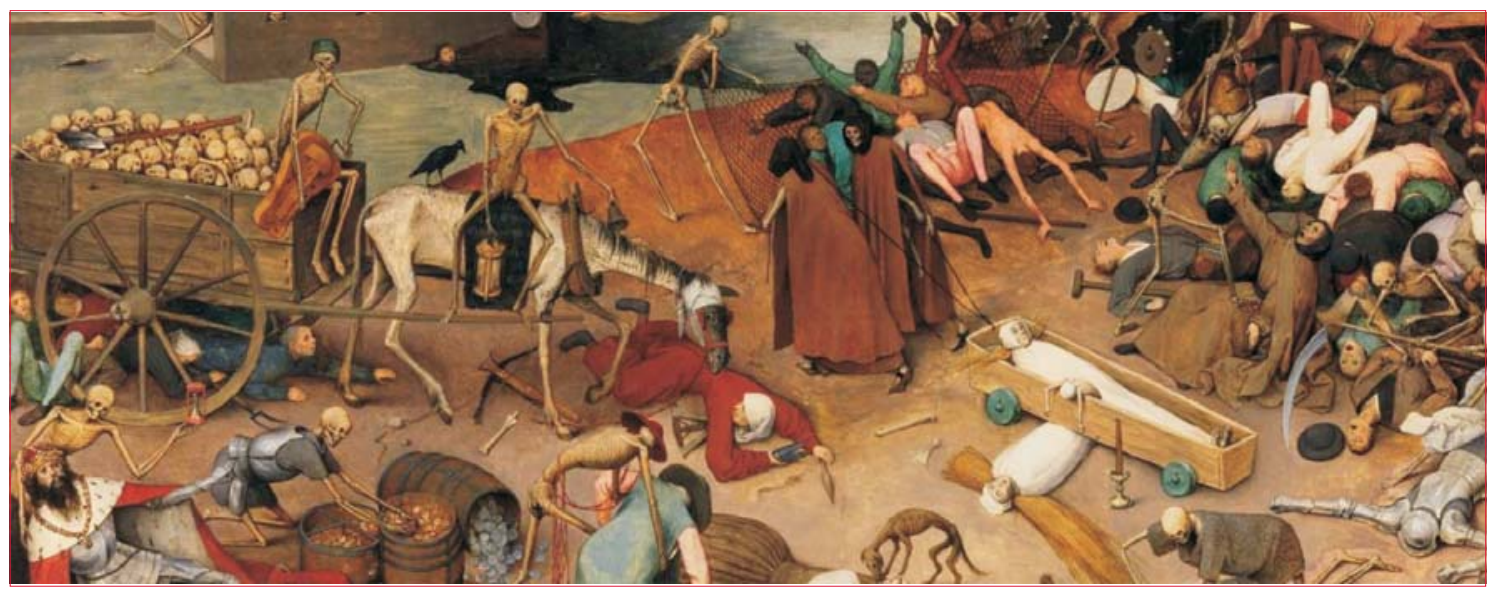

Figura 2. El triunfo de la muerte. Pieter Brueghel El Viejo (1562-1563). Óleo sobre tabla (detalle). Museo del Prado, Madrid. Causas extranaturales producen una mortandad de la que nadie se salva.

se extendió desde Etiopía a Atenas, donde murió la tercera parte de su población. En esta epidemia muere Pericles. Los espartanos huyeron por temor al contagio. Una losa encontrada en el Partenón muestra a Atenea, diosa de la guerra y la filosofía, pensativa con su lanza clavada al suelo y señalando su frente con el índice de su mano izquierda, mientras mira una lápida. Según algunos, la diosa llora las muertes que se produjeron debido a la peste que asoló a la polis (figura 1).

El hecho de que no se conociera la causa cierta de la enfermedad, (en esta oportunidad, y hasta el siglo XIX) favoreció que se desplegaran dos mecanismos interpretativos de la desgracia colectiva: era producto de seres endemoniados o de la ira de los dioses (figura 2); o bien se acusó al semejante, al otro, como causante directo de la calamidad, de ahí que la crisis de la otredad fue y en buena medida sigue siendo, la manifestación más primitiva y general de las epidemias. La vida social se desarticula dado que el semejante pasa a ser un peligro potencial para la integridad propia. El otro adquiere su plena dimensión, es específicamente alguien distinto a lo constitutivo del yo, alguien que "me puede enfermar y matar". El riesgo de discriminación es evidente.

En el 166 dC, Roma es la ciudad afectada con la peste antonina, que probablemente fue de viruela. Se estima que murieron cinco millones de individuos y conocemos algo de ella gracias a las descripciones de Galeno, que la vivió directamente.

Roma se vio nuevamente afectada en el $251 \mathrm{dC}$ con la peste de Cipriano, de causa discutida.

En el 542 el Imperio Bizantino fue atacado por el primer brote conocido de peste bubónica cuya segunda oleada fue la conocida peste negra del año 1346, que causó 30 millones de muertes. Los historiadores le adjudican a la peste negra (siglo XIV) efectos más amplios que la muerte de personas: estiman que el mundo cambió en las décadas siguientes, hubo relajamiento de las costumbres, comienza a derrumbarse el régimen feudal, se produce una carencia de mano de obra y se alumbra el Renacimiento. La oleada de enfermedad y muerte fue atribuida a los judíos que eran, por razones de higiene, menos susceptibles de enfermar de peste.

El Decamerón de Boccaccio da cuenta de la situación que se vivía por aquellos tiempos en Europa. Diez jóvenes, siete mujeres y tres varones huyen de la peste negra y se refugian en una finca en las afueras de Florencia, donde, para sobrellevar el aislamiento cada uno narra un cuento durante diez noches (de ahí el nombre de la obra), totalizando cien cuentos, algunos de tinte erótico. Boccaccio escribió este libro desde 1347-1348 y lo terminó en 1353, año en el que se produjo el fin de la epidemia. Describe con crudeza los efectos físicos, sociales y emocionales de la peste:

"iCuántos valerosos hombres, cuántas hermosas mujeres, cuántos jóvenes gallardos a quienes no otro que Galeno, Hipócrates o Esculapio hubiesen juzgado sanísimos, desayunaron con sus parientes, compañeros y amigos, y llegada la tarde cenaron con sus antepasados en el otro mundo!"(3).

Esta misma peste atacó a Inglaterra en el siglo XVII, en los años 1665 y 1666 . Uno de los tantos habitantes de la ciudad que debió suspender sus actividades fue Isaac Newton, que durante el fecundo confinamiento a que se vio obligado comenzó sus trabajos sobre la ley de la gravedad. La peste fue provocada por la picadura de las pulgas de los roedores y en el caso de Londres solo se vio amainada debido al incendio de la ciudad ocurrido entre el 2 y el 5 de setiembre de 1666 .

En 1485 una epidemia de gripe conocida como sudor inglés asoló el norte de Europa. 


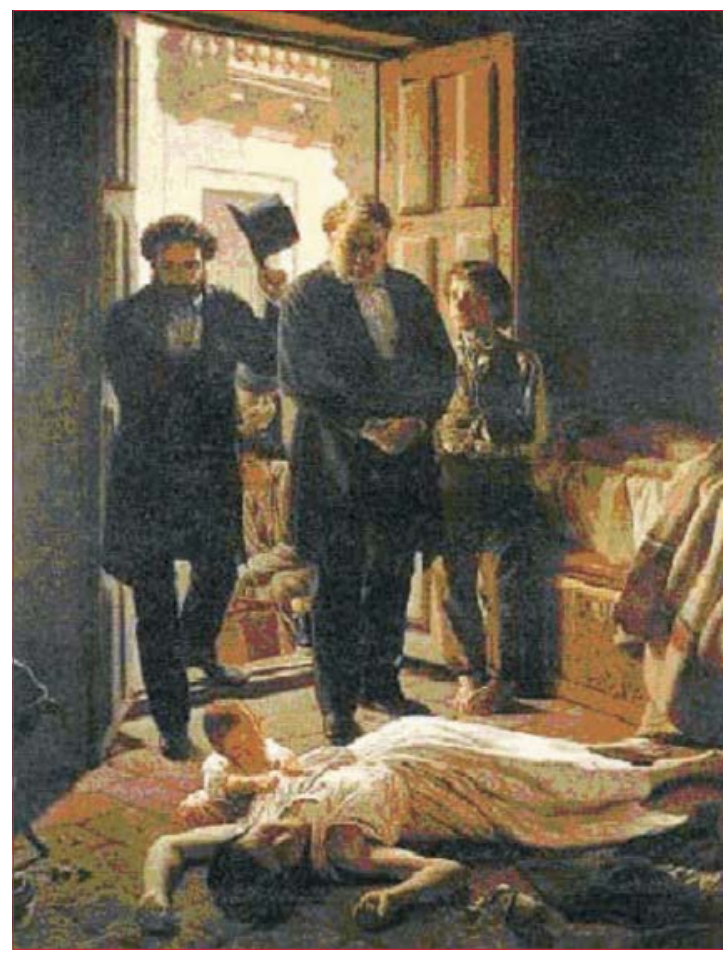

Figura 3. Un episodio de fiebre amarilla en Buenos Aires (1871). Juan Manuel Blanes. Museo Nacional de Artes Visuales, Montevideo, Uruguay.

En el siglo XIX el hecho más destacado fue la epidemia de fiebre amarilla, causada por un virus que fue aislado recién en 1927. Este flagelo atacó a Buenos Aires en 1871 y allí, nuevamente, se adjudicó el mal a los semejantes, en este caso a inmigrantes italianos por su pobre forma de vida. El descubrimiento del vector de la fiebre amarilla (el mosquito Aedes aegypti) se debe al médico cubano Carlos Finlay, que describió el mecanismo en 1881 y en cuyo recuerdo se conmemora el Día del Médico, el 3 de diciembre.

El pintor uruguayo Juan Manuel Blanes inmortalizó la situación vivida en la vecina capital en su mundialmente célebre pintura Un episodio de fiebre amarilla en Buenos Aires (1871) (figura 3), que se encuentra en el Museo de Artes Visuales de Montevideo. Allí se representa un hecho real, ocurrido el 17 de marzo de 1871 en un conventillo de Balcarce 384 , y muestra a una mujer, llamada Ana Brisitiani, fallecida por la enfermedad, tendida en el suelo, mientras un niño pequeño busca beber de su seno. La escena es observada por dos personajes también reales, el Dr. Roque Pérez, abogado, y el Dr. Manuel Argerich, médico, integrantes de la Junta Popular que se formó para atender a los enfermos y disponer los cadáveres en aquella circunstancia. Ambos morirían poco después víctimas de la enfermedad.

Durante el ataque de fiebre amarilla en Uruguay, que comenzó en marzo de 1857, fallecieron

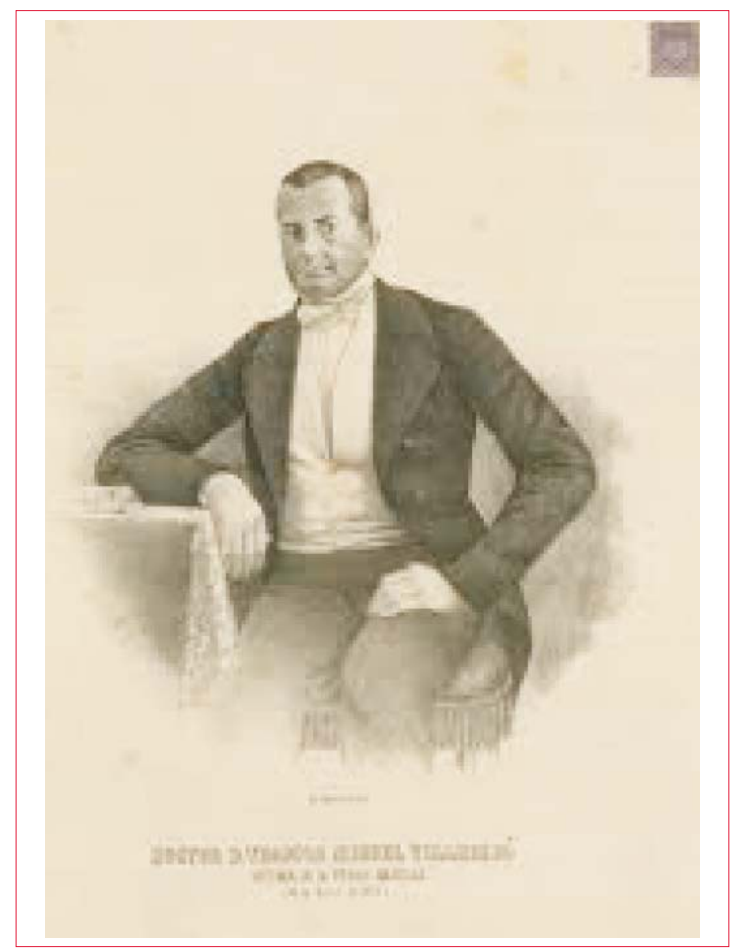

Figura 4. Dr. Teodoro Vilardebó (1803-1857).

más de 1.000 personas, entre ellas, el Dr. Teodoro Vilardebó, primer médico uruguayo (figura 4).

A fines de la Primera Guerra Mundial hizo su presencia la llamada gripe española, que no tuvo origen en España, sino que fue llevada al viejo continente por soldados extranjeros que participaron en el conflicto. Nuevamente es patente la tendencia a despojarse de responsabilidades propias cuando se producen estos males. La epidemia duró dos años y la mortalidad fue asombrosa, ya que perdieron la vida entre 25 y 50 millones de personas.

En 1968, se registró la gripe de Hong Kong, que afectó a 2 millones de personas.

Desde 1981 se observa la pandemia de sida, que lleva 60 millones de personas infectadas y 30 millones de muertos. Como se ha presentado a lo largo de todo este tiempo desde entonces, no impacta tanto como las epidemias que registran curvas empinadas de contagio y muerte en función del tiempo. El sida ha dado lugar a una rica producción metafórica que fue expuesta y analizada por Susan Sontag en un libro memorable ${ }^{(4)}$.

Interesa destacar el coronavirus SARS en 2003, con 8.000 infectados y 700 muertos; la gripe H1N1 en 2009, que provocó 18.000 muertes, y el ébola en 2014, que provocó 4.500 fallecimientos en seis meses.

En 2012-2015, el síndrome respiratorio en Medio Oriente provocado por una variedad de coronavirus llamado MERS-CoV. 


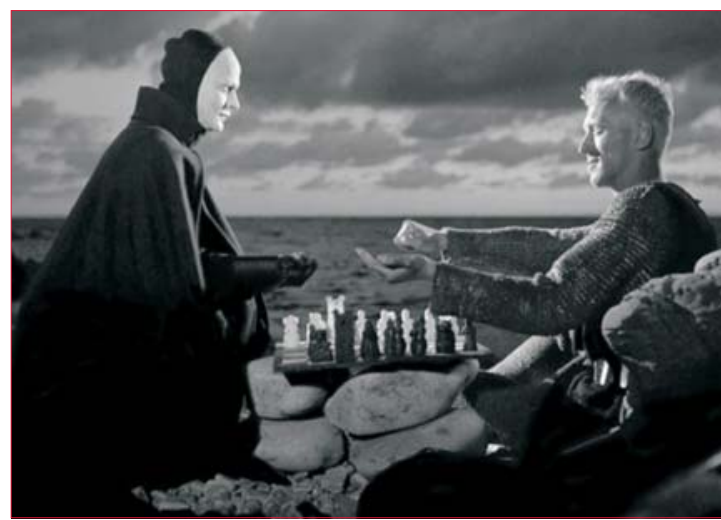

Figura 5. El séptimo sello (1957). Película de Ingmar Bergman. Un caballero que vuelve de las Cruzadas se halla en una comarca diezmada por la peste en la Suecia medieval del siglo XIV. Allí, lo encuentra la Muerte con la que juega la última partida de ajedrez. Ante su sorpresa, la Muerte se presenta como la que "he caminado siempre a tu lado".

En 2014, el virus del Zika provocó 4.000 muertos y miles de niños afectados por microcefalia.

$Y$ finalmente la pandemia que nos ocupa en este momento, de COVID-19, enfermedad descubierta entre noviembre y diciembre de 2019 en China ante la desatención y frivolidad de muchos, y de algunos líderes mundiales. El COVID-19 alcanzó una expansión planetaria y obligó a declararla pandemia por la Organización Mundial de la Salud, el 11 de marzo de 2020. La trama de indiferencia y culpa aún está por determinarse. Se repite la historia desde la más lejana antigüedad.

\section{La peste y la filosofía}

Pocas son las circunstancias vitales que permiten hacer un recorrido por los diversos temas que hemos abordado en esta serie, como sí lo permiten las pestes (o epidemias, o pandemias).

Desde los fines de la medicina, pasando por la relación médico-paciente, la reconfiguración del concepto mismo de enfermedad, las metáforas en medicina, el dolor y el sufrimiento, las miradas al cuerpo, hasta la relación de las personas y especialmente de los médicos y del personal de salud con la muerte, todos los asuntos abordados hasta ahora en esta revista se ven concernidos por la pandemia y la forma de vivenciarla.

La filosofía no queda afuera de este enfoque.

No voy a entrar en el análisis de la coyuntura realizado por filósofos contemporáneos de gran nombradía y en algún caso, de cierta importancia, que se han aventurado a interpretar, a mi criterio en forma apresurada, la actual pandemia de coronavirus. Algunos han lanzado valoraciones fuera de la realidad (como Giorgio Agamben, que le resta im- portancia en sí a la invasión del coronavirus y estima que es una excusa para disponer de las vidas con el fin de ofrecerlas a un sistema de explotación mundial, o Slavoj Zizek, que pronostica una salida revolucionaria a la crisis y el fin del capitalismo como consecuencia de los nuevos valores que imperarán y la atención al último llamado que hace la naturaleza diezmada). Más mesurado, Byung Chul Han pronostica una acentuación de los rasgos egoístas de la sociedad y ningún cambio trascendente. Allá ellos con su, a mi juicio, desmesurada futurología. Es muy frecuente oír por estos días que estamos en el amanecer de un nuevo tiempo. Sin restarle importancia a los cambios que será dable observar, como consecuencia de la aceleración de avances tecnológicos preexistentes, y quizás de la necesidad de respetar ciertas modificaciones del comportamiento social, es poco probable que "las masas" experimenten súbitamente una radical transformación de los valores imperantes, cosa que depende, fundamentalmente, de la resignificación de la vida que es, en última instancia, producto de la elaboración individual.

En cambio, me voy a referir, muy brevemente, a dos grandes exponentes de la filosofía: el alemán Martín Heidegger y el francés Michel Foucault, que nos ponen en camino de comprender los límites y entramados a los que nos vemos expuestos en este momento.

\section{La presencia concreta de la muerte}

La epidemia de COVID-19 genera sentimientos variados en las personas. Como toda epidemia, es capaz de exponer, de sacar de lo más íntimo de las personas concretas, lo más benévolo y solidario de la naturaleza humana, y también lo más perverso y maligno que constituye esa misma naturaleza. El ser humano convive con un angelito en un hombro y un diablito en el otro, y con esa dual y antagónica compañía vamos por la vida.

Pero también participamos en esta desventura con miedo, a veces paralizante. Es que tomamos conciencia, en virtud de la amenaza que significa este enemigo invisible, de la finitud de nuestra existencia. Los límites de la vida no se hacen habitualmente perceptibles de forma tan dramática en una enfermedad de curso natural -aunque ciertamente hay muchas que nos llevan a la muerte-, y eso es así porque participamos de un relato de protección o salvaguarda de la vida en virtud de la ciencia y también de las desmesuradas expectativas depositadas en el poder de la medicina. La medicina siempre sale al encuentro de la enfermedad proporcionando esperanza de curación o paliación. En una pandemia, 
el infortunio es colectivo, nadie está a salvo, todos estamos en riesgo de enfermar y morir. Las víctimas comparten una imagen de masividad e instantaneidad, caen de un momento a otro, no son casos aislados ("hoy se reportaron x casos", nos dice el parte diario). El enemigo tira a la masa, los caídos se hacen públicos, no van enfermando y muriendo en el anonimato como si fueran por infarto, cáncer o accidentes carreteros, sino que se contabilizan para el informe que nos pone al tanto de "cómo va la guerra”.

Esa vivencia de situación límite no es más que la reagudización temporal, fugaz, de una esencia mortal que nos singulariza como especie consciente, y que disimulamos en la vida cotidiana con variadas y a veces "distinguidas" formas de existencia que enmascaran nuestro único final cierto que es el morir. Heidegger nos dice que somos seres arrojados a la existencia, somos ahí, de forma concreta (Dasein), abiertos a un sinnúmero de posibilidades, pero la posibilidad última e infaltable siempre es la muerte, a la que define como la imposibilidad de toda posibi$\operatorname{lidad}^{(5)}$.

Las epidemias hacen patente a la muerte como quizás ninguna otra circunstancia humana. Más acá de esta vivencia actualizada e inminente (figura 5), la pandemia revisa y reconfigura la vida en sociedad. El encuentro con el otro, base del ser social del hombre, se ve alterado. El encuentro (etimológicamente del latín in contra, en contra, salir al encuentro) se transforma en riesgo: la otredad es desconfianza, el otro es un ser con el que se puede compartir lo peor, el enemigo invisible anida en un semejante.

La forma de morir durante la pandemia actual merecería un capítulo aparte. Ya no solo se muere en soledad (como acto íntimo la muerte siempre es solitaria, íntima, individual e intransferible), sino que se muere casi exclusivamente de forma institucionalizada, en centros de tratamiento intensivo y ayudados hasta último momento por respiradores, alejados de familiares y amigos, en un estado que llamaríamos de radical soledad. Se trata de una soledad impuesta no solo por las peculiaridades de los lugares de internación, sino que es una soledad absoluta, que se le impone también al cadáver, ya que la reunión a su alrededor puede constituirse en un "foco" para los que permanecen vivos.

Este comportamiento es novedoso: la forma de morir institucionalizada fue muy mal vista en otros tiempos.

Daniel Defoe, autor de Robinson Crusoe, en su Diario del año de la peste (1722), relata de forma ficticia hechos relacionados con la epidemia de peste que alcanzó a Londres en 1665, a la que ya nos he- mos referido. Allí se hace una referencia a la muerte en esa época, solitaria también pero no institucionalizada. Se pregonaba lo siguiente: "Que el entierro de los muertos se efectúe a las horas más convenientes, ya sea antes de la salida del sol o después de la puesta del sol (...) que a ningún vecino o amigo se le imponga la obligación de acompañar el cadáver a la iglesia o entrar en la casa contaminada (...) Yque ningún niño esté cerca del cadáver, el cajón o la tumba en cualquier iglesia o cementerio (...) y todas la reuniones públicas por otros entierros quedan prohibidas...(6).

Para nuestro medio, es muy recomendable la lectura de la obra de José Pedro Barrán sobre la sensibilidad en Uruguay. En relación con las epidemias de fiebre amarilla del siglo XIX, hay unas páginas de lectura deleitosa -aun siendo trágicos los hechos-, donde se narra el caso de los hermanos Federico y Rosa Cabot, fallecidos de 21 y 15 años de edad, respectivamente, en el Hospital de Caridad de Montevideo, pocos días después de la muerte del Dr. Vilardebó. Se desenvolvió sobre el padre que los había depositado en aquel "moridero", toda la sensibilidad de la sociedad contemporánea. "¿Qué había hecho este padre? ¿Acaso pegado con violencia e incomprensión llevándolos al suicidio? No, este tipo de conducta se admitía. ¿Les había negado asistencia médica? No, en realidad los había llevado al Hospital donde estaban todos los médicos. Es cierto, siendo pudiente ni siquiera les pagó una pieza aparte, lo que era posible y también le fue reprochado. $\mathrm{Su}$ transgresión indisculpable fue dejarlos en un lugar sin que él los haya visto morir, sin que ellos pudiesen darle el último adiós”(7).

Miedo, nuevo diseño de las relaciones sociales, presentificación de la muerte... no se agotan ahí las dimensiones de las pestes. Hay una resignificación del tiempo. Vivimos en una temporalidad volcada a la sociedad, al discurrir veloz y anestesiante de la existencia productiva y "barullenta"; de repente, el tiempo visto desde la cuarentena se torna propicio para la interioridad, para esas excursiones por las avenidas del alma tan desmerecidas por la sociedad moderna, a la que solo parece importarle la eficacia del ser humano.

\section{La presencia del poder}

Una mirada por la filosofía más reciente, advierte rápidamente que en estas circunstancias de pandemia es donde se ve con toda su intensidad el efecto de las relaciones de poder y de la biopolítica, de la que nos habló Michel Foucault. El poder del Estado como regulador de las vidas es innegable, y según parece innegociable, porque es el accionar del Esta- 
do el que garantiza, en última instancia, el bienestar de la colectividad. La asimetría de poder entre el Estado y los ciudadanos es evidente. Por debajo de ese vínculo asimétrico es posible ver relacionamientos horizontales y solidarios que contribuyen al relativo bienestar que se puede obtener en estos momentos, pero en última instancia es el Estado, con sus normas y vigilancia, el que trabaja día y noche para evitar males mayores y la debacle generalizada. Es cierto que los ciudadanos le hemos otorgado esas potestades, pero eso no es obstáculo para señalar la disparidad de fuerzas. Salvo las apelaciones a la libertad y responsabilidad individuales, tratando de no hacer obligatorios ciertos comportamientos en la sociedad, todo se parece al "vigilar y castigar" foucaltiano(8). Hay quienes ven en esto una señal peligrosa y un futuro distópico: el individuo se manifiesta inerme por desinformación o egoísmo, y ello podría propiciar regímenes autoritarios y violaciones a los derechos humanos.

Un efecto destacado de esta pandemia es la revalorización de la medicina y de la ciencia en contraposición al conocimiento vulgar. La modernidad se ha caracterizado en buena medida por la relativización de los saberes: las relaciones entre el conocimiento experto e inexperto se han horizontalizado, "vale igual lo que yo opino que lo que tú opinas", aun en temas de gran complejidad; esa tendencia se ha revertido en gran medida frente al riesgo límite que significa la pandemia y se adueña del paisaje una importante expectativa depositada en la medicina y en la ciencia acerca de una solución al problema sanitario que nos preocupa. Se reconoce y saluda la presencia intachable de médicos y demás personal de la salud en la primera línea de batalla con gestos casi heroicos. Es importante, asimismo, la búsqueda de la evidencia científica a través de asesoramientos calificados para guiar mejor las decisiones colectivas.

Baltasar Aguilar Fleitas,

https://orcid.org/0000-0001-8916-6987

Este artículo fue aceptado para su publicación por: Editor jefe Dr. Gerardo Soca.

\section{Bibliografía}

1. Camus A. La peste. Barcelona: EDHASA; 2005

2. Harari YN. Homo Deus. Breve historia del mañana. Montevideo: Sudamericana; 2018:16.

3. Boccaccio G. Decamerón. Madrid: Ediciones Cátedra; 2007.

4. Sontag S. La enfermedad y sus metáforas y el SIDA y sus metáforas. Buenos Aires: Aguilar, Altea, Taurus, Alfaguara; 1996.

5. Heidegger M. El ser y el tiempo. Buenos Aires: FCE; 2009.

6. Defoe D. Diario del año de la peste. Barcelona: Alba; 2006: 77.

7. Barrán JP. Historia de la sensibilidad en Uruguay. Montevideo: Banda Oriental; 2012: 160-4.

8. Foucault M. Vigilar y castigar: nacimiento de la prisión. Buenos Aires: Siglo XXI Editores Argentina; 2002. 